\title{
MME DE STAËL: LITERATURA E TRADUÇÃO
}

\author{
Marie-Hélène Catherine Torres* \\ Universidade Federal de Santa Catarina
}

\begin{abstract}
Resumo: O presente artigo traz, num primeiro momento, uma reflexão teórica a respeito do conceito de literatura comparada, principalmente ligado à alteridade e à dimensão estrangeira. Em seguida, mostramos como e porque De la littérature considérée dans ses rapports avec les institutions sociales [Da literatura considerada na suas relações com as instituições sociais] de Mme de Staël é considerada um verdadeiro trabalho "comparatista". Por fim, veremos como a interculturalidade e a visão de perfectibilidade da escritora envolvem a tradução de forma a contribuir ao desenvolvimento das Letras pelo conhecimento de outras literaculturas. Palavras-chave: Tradução literária. Literatura comparada. Mme de Staël. Literacultura.
\end{abstract}

\section{MME DE STAËL: LITERATURE AND TRANSLATION}

\begin{abstract}
This paper presents, at first, a theoretical reflection on the concept of Comparative Literature, mainly connected to the otherness and foreign dimension. We then show how and why the book De la littérature considérée dans ses rapports avec les Institutions sociales [On Literature Considered in its Relations with Social Institutions] from Madame de Staël is considered a real "comparative" work. Finally, we will examine how interculturalism and perfectibility according to the writer point
\end{abstract}

\footnotetext{
* Possui Doutorado em Estudos em Tradução - Katholieke Universiteit Leuven (2001). Pós-Doutorado pela Universidade de Minas Gerais (2011). Coordena o Doutorado Interinstitucional (DINTER) da PGET/UFSC com a UFPA (20152019). É Professora Associada da Universidade Federal de Santa Catarina. Florianópolis, Santa Catarina, Brasil. E-mail: marie.helene.torres@gmail.com
} 
of view involve translation in order to contribute to the development of Letters by the knowledge of other liteculturas.

Keywords: Literary Translation. Comparative Literature. Mme de Staël. Literaculture.

O ensaio de Mme de Staël De la littérature, considérée dans ses rapports avec les institutions sociales [Da literatura considerada na suas relações com as instituições sociais] foi publicado em 1800, ou seja, na passagem de um século para o outro. Presságio de uma nova era, o método de análise de Mme de Staël permite considerar a literatura sob uma nova luz, ou seja, não somente em relação às instituições sociais, mas ainda como parte integrante destas. De la littérature teve um papel fundamental na criação da história literária e, de forma mais geral, das ciências humanas. Para Mme de Staël, as trasnformações social e literária estão intimamente ligadas em virtude da lei histórica da perfectibilidade do espírito humano. Apreende a criação e a análise literárias numa dinâmica tal que se torna precursora da crítica comparativa. Sem nunca perder de vista o seu conceito de perfectibilidade, a autora faz reflexões sobre a tradução que contribuem ao desenvolvimento das Letras pelo conhecimento de outras literaculturas, isto é, literaturas/culturas.

Numa conferência em novembro de 1997, o professor Daniel-Henri Pageaux da Sorbonne Nouvelle, Paris III, refletiu sobre a natureza do ato comparatista ${ }^{1}$, propondo sugestões quanto à função deste ato: "Mas vocês, os comparatistas, o que comparam? A esta pergunta, falsamente ingênua e realmente mal-intencionada, $\mathrm{o}$ comparatista deve responder: nada". (PAGEAUX, 2005)

Literatura comparada não é comparação literária. Não se trata de transpor simplesmente para as literaturas estrangeiras os paralelos das antigas retóricas. Pageaux recusa afirmações segundo as quais tudo é comparado ou comparável. Cita a esse respeito George Steiner (STEINER, 2001) cujo livro foi traduzido em português em 2001 por Maria Alice Máxima sob o título: Nenhuma Paixão Desperdiçada. Steiner chama de "comparativo" qualquer ato de recepção de uma forma significativa, ou seja, linguagem, 
arte ou ainda música. Uma mera declaração de preferência seria tachada de "comparação". Ler é/seria comparar. Não tenho certeza de concordar com isso. Pode ser, mas Pageaux não quer abordar a disciplina de literatura comparada deste modo e prefere se referir à disciplina como sendo o estudo das relações espirituais internacionais, expressão que ele empresta de La littérature comparée de Marius-Fr. Guyard (1951). Pageaux propõe o seu proprio conceito. Para ele, de início, a literatura comparada se origina de uma tomada de consciência, isto é, de uma problematização e da dimensão estrangeira de um texto, um escritor, uma literatura, uma cultura. A questão da alteridade é, para ele, constitutiva da disciplina, ou seja, a comparação e a dimensão estrangeira. O que chamo de literacultura.

Pageaux apresenta também um estudo histórico e teórico da disciplina de literatura comparada. O que nos interessa aqui, é que ele elege Heródoto e Mme de Staël como patronos da disciplina. Seguindo uma crítica de identificação ou crítica criativa e reflexiva, Pageaux acrescenta o pensamento da alteridade e da atividade comparatista, no sentido de variações comparativas entre os gregos e os não-gregos, ou seja, os outros. Antes dele, Jean-Joseph Texte, em 1885, autor da primeira tese de literatura comparada intitulada Jean-Jacques Rousseau et les origines du cosmopolitisme littéraire, já destacava o trabalho "comparatista" de Madame de Staël. Ele mostrou como a distinção fundamental entre literaturas do Norte e literaturas do Sul se baseia numa comparação precedida por uma análise que delimita os objetos da futura comparação. Texte faz uma referência direta à obra de Mme de Staël De la littérature, considérée dans ses rapports avec les institutions sociales publicada em 1800 [Da literatura considerada nas suas relações com as instituições sociais] que continua sem tradução no Brasil. No capítulo XI de De la Littérature, intitulado "De la littérature du nord" [Da literatura do norte], Mme de Staël afirma que os poetas ingleses conservaram a imaginação do norte, a que gosta da beira mar, do barulho dos ventos, da fauna selvagem, enfim a imaginação que leva para um outro mundo. Ela escreve : 
Toutes mes impressions, toutes mes idées me portent de préférence vers la littérature du nord; mais ce dont il s'agit maintenant, c'est d'examiner ses caractères distinctifs. (STAÉL, 1991, p. 205).

[Todas minhas impressões, todas minhas ideias me levam preferencialmente para a literatura do norte; mas trata-se agora de examinar seus caracteres distintivos.]

A partir daí, ela explicita porque prefere a literatura do norte. Segunda ela, o clima influencia certamente a visão de mundo de cada povo: no norte, os povos são melancólicos, sonham com feitos extraordinários e tem mais intensidade; no sul, os poetas mesclam exageradamente a natureza com os sentimentos do coração, o que faz com que se movimentam mais do que pensam. Os povos do norte se ocupam mais com a dor do que com prazeres por isso sua imaginação é mais fecunda.

Na mesma obra, Mme de Staël (STÄ̈L, 1991, p. 87) explicita seu conceito de perfectibilidade das civilizações (principalmente a partir de Shaftesbury) e defende a literatura engajada, pois, para ela, a literatura não é somente arte, mas é também um instrumento de análise do homem e de transmissão do Século das Luzes. Mme de Staël empresta de Rousseau no seu Discours sur l'origine de l'inégalité [Discurso sobre a origem da desigualdade] a noção de perfectibilidade, que é uma faculdade específica do homem em oposição ao animal, a de transformar a si próprio conforme as circonstâncias enquanto agente livre. A perfectibilidade designa então uma capacidade dinâmica de metamorfose e mudança. Mme de Staël aplica a ideia de perfectibilidade à literatura, literatura entendida de forma mais abrangente, mais ampla, isto é, a literatura como o estudo do ser humano, dos seus costumes (conforme modelo de Montesquieu), de sua história, de sua filosofia e das suas instituições sociais. Mme de Staël demostra sua fé no progresso e na elevação contínua do espírito humano. Ela era convicta de que a 
literatura era a expressão da sociedade. Mas, infelizmente, aquela época era uma época de normalização ideológica (estou pensando aqui em Bonaparte) e a literatura talvez não tenha desenvolvido o devido/esperado papel social, político, cultural.

\section{Quem era Mme de Staël para ser elevada à Patrona da Literatura Comparada?}

Madame de Staël, filha de Jacques Necker, banqueiro e ministro das Finanças de Louis XVI, era conhecida dos historiadores do século XIX. Suas Considérations sur la Révolution française [Considerações sobre a Revolução francesa], criticada assim que foi editada por J.-C. Bailleul e L. de Bonald, conforme o estudo de Claire Gaspard ${ }^{2}$, foram muito lidas na época da sua publicação em 1818, no ano seguinte de sua morte. Bestseller na sua época, publicado várias vezes até 1881 , o livro teve que esperar até 1983 para encontrar uma nova impressão na edição crítica de Jacques Godechot Tallandier. Seu mérito principal foi, no seu tempo, descrever e analisar o grande cíclo revolucionário, dos antecedentes da Revolução até a Restauração. Este texto é ao mesmo tempo a narração de uma testemunha excepcional, intimamente envolvida nos principais eventos da Revolução e um exercício de reflexão sobre as origens e a natureza desses eventos.

No entanto, a maioria dos historiadores do século XIX não menciona o nome de Mme de Staël. Uma minoria de historiadores, como Louis Blanc, Michelet, ou ainda Jaurès, a cita como testemunha dos últimos "Etats-Généraux" de 1789, isto é, a Assembléia das Três Ordens, Clero, Nobreza e Povo, convocada pelo Rei. Somente Michelet (1855), no seu livro Les femmes de la Révolution [As mulheres da Revolução], menciona, en passant, o papel político do salão literário de Mme de Staël e da sua obra literária, a qual não parece apreciar muito. O silêncio dos historiadores do século XIX a respeito de Mme de Staël é surpreendente. Como explicá-lo? O que foi ocultado, inclusive por Michelet, é o pensamento político dessa mulher intelectual que foi Mme de Staël. É como se a 
história politico-literária não a tivesse percebido: ou porque o rosto de uma mulher os impediu de ver nela uma pensadora política, ou talvez porque a ala liberal que ela representava só teria destaque na historiografia do final do XIX - início do Século XX. Barbey d'Aurevilly (1808-1889) escritor francês, por exemplo, incluirá em 1878 no $5^{\circ}$ volume Des Euvres et des hommes [Das obras e dos homens] um artigo sobre de Mme de Staël (AUREVILLY, 1878 a). Ele afirmará, paradoxalmente, que ela era, de um lado, um gênio essencialmente feminino e que era preciso voltar a publicar as suas obras e sua correspondência e, do outro lado, que tais publicações provariam que "une femme ne peut écrire ni penser comme un homme" [uma mulher não pode escrever nem pensar como um homem]! Isso pode explicar porque ela esteve tão invisível na história literária da época.

\section{A tradução e a perfectibilidade}

Para Mme de Staël, a literatura francesa só podia se regenerar através dos ideais republicanos e da influência das literaturas estrangeiras. Em oposição ao classicismo e a uma concepção nacionalista totalitária instaurada pelo regime de Bonaparte ${ }^{3}$, Mme de Staël e seus amigos enxergavam a salvação dos povos e das literaturas modernas por meio de intercâmbio, de troca dos valores culturais e artísticos. É o liberalismo político traduzido para o espaço literário e o campo artístico. A tradução enquanto mediação com o estrangeiro permite revelar o espírito nacional e desempenha um papel central na disseminação e na circulação das ideias. Assim, a perfectibilidade das Letras e do espírito humano se modelaram através do enriquecimento do caráter estrangeiro, apreendido enquanto fator de dinamismo social.

Segundo Jane Elisabeth Wilhelm (WILHELM, 2004) da Universidade de Genebra, após a Revolução, o Castelo de Coppet nas margens do lago de Genebra, lugar de exílio de Mme de Staël, aparece como um lugar privilegiado de diálogo entre as culturas: 
as da Itália, da Inglaterra, terra de liberdade e do liberalismo para o grupo de Coppet e da Alemanha, representante de uma nova literatura, a literatura romântica. A elite liberal, o grupo de amigos de Mme de Staël, conhecidos como o grupo de Coppet, publicará, a partir do diálogo entre as literaturas europeias, algumas das mais importantes obras da época. Sob a égide das relações interculturais e da tradução, que marca o início da literatura comparada, foram publicadas obras como:

- Corinne ou l'Italie e De l'Allemagne e Considérations sur la Révolution française de Mme de Staël

- Adolphe, Cécile, Wallstein de Benjamin Constant que terá uma adaptação por parte de Schiller

- Comparaison des deux Phèdre, Cours de littérature dramatique de Schlegel

- Recherche sur la nature et les lois de l'imagination de Bonstetten

- Tableau de la littérature française au XviII siècle de Prosper de Barante

- Histoire des républiques italiennes e De la littérature du midi de l'Europe de Sismondi.

Para o Grupo de Coppet, "uma cultura só evolui através dos seus contatos com outras" segundo Todorov (1986, p. 16), isto é, uma cultura se constitui por um constante trabalho de tradução. Mme de Staël publicará, em janeiro de 1816, na revista italiana de Milão, Biblioteca italiana, um ensaio intitulado "Sulla maniera e la utilità delle traduzioni", ["Do espírito das traduções" (STAËL, 2004)], conforme Lieven d'Hulst (1990, p. 224-244) durante sua segunda viagem para a Itália. É o cosmopolitismo, isto é, o espírito das traduções, que favorece o livre comércio das ideias e o diálogo com o outro, o estrangeiro. No ensaio, Mme de Staël conceitualiza a tradução da seguinte forma: 
Não há mais eminente serviço que se pode prestar à literatura de que transportar de uma língua para outra as obras primas do espírito humano. Existem tão poucas produções de primeira ordem; o gênio, em qualquer área que seja, é um fenômeno tão raro, que se cada nação moderna fosse reduzida a seus próprios tesouros, seria sempre pobre. Alias, a circulação das idéias é, de todos os tipos de comércio, o que tem as mais seguras vantagens. (STAËL, 2004).

Para favorecer os progressos das Luzes e do pensamento, bem como para garantir a liberdade graças a uma opinião pública esclarecida, não convém imitar, avisa Mme de Staël, mas sim "emprestar" a fim de "conhecer" e de "libertar-se de certas formas convencionadas". As tranferências facilitam a passagem para o universal dentro das redes de trocas da cultura do cosmopolitismo. Na sua visão de perfectibilidade, a tradução contribue ao desenvolvimento das Letras pelo conhecimento de outras culturas europeias, as literaculturas, e ao renascimento de toda a literatura francesa pela renovação das fontes de inspiração graças à mediação com o estrangeiro, como ela o afirma no ensaio:

\begin{abstract}
Ora, é para o universal que deve inclinar-se quando se quer bem aos homens. Diria mais: mesmo entendendo bem as línguas estrangeiras se poderia saborear ainda através de uma tradução bem feita na sua própria língua, um prazer mais familiar e íntimo. Estas belezas naturalizadas proporcionam ao estilo nacional novas feições e expressões mais originais. As traduções dos poetas estrangeiros podem, com mais eficácia que qualquer outro meio, preservar a literatura de um país dessas feições banais que são os mais certos sinais de sua decadência. (STAËL, 2004).
\end{abstract}

As expressões "belezas naturalizadas", "novas feições” e "expressões originais" anuncivam uma nova sensibilidade estética em tradução cuja condição essencial era o espírito de liberdade. As pa- 
lavras “original" e "originalidade" remetem no imaginário de Mme de Staël à natureza primitiva de uma tipologia nacional, à um estado de natureza como o de Rousseau onde o natural é sinonimo para ela de verdade, diversidade e cores. A tradução enquanto criação e não enquanto imitação contribue a reforçar a identidade nacional. Ao resgatar a riqueza de outros povos, uma literatura pode renovar-se e permitir a existência de novas formas culturais. A teoria da tradução permite assim a uma nação de tornar-se plena. Visionária, Mme de Staël era uma pioneira da antropofagia literacultural.

Ao denunciar, no seu ensaio, a escola do Século XVIII, ou seja, as "Belas Infieis", ela avisa os italianos contra os limites do neo-classicismo e os convidavam a abrir-se às influências europeias:

\begin{abstract}
Mas, para que este trabalho seja realmente proveitoso, não há de dar, como os franceses, sua própria cor a tudo que se traduz; e mesmo devendo transformar em ouro tudo que toca, não deixaria de obter um só resultado: não poderia alimentar-se com ele; não encontraria dentro alimentos novos para o pensamento e veria sempre o mesmo rosto com enfeites apenas diferentes. (STAËL, 2004).
\end{abstract}

O feito tradutório, segundo Mme de Staël, não consiste em transpor simplesmente pensamentos estrangeiros numa forma francesa anexando o outro dentro de uma cultura hegemônica, mas sim em apreender o sentido singular, a tonalidade e a energia de um texto. A obra estrangeira não poderia mais ser considerada como "bárbara", pois seu valor se destaca nas suas diferenças e originalidade. A ideia da tradução, como ato ilustrando de maneira privilegiada as trocas ou o "comércio" intelectual, se encontra também formulada, na mesma época, por Schleiermacher e Goethe, ligada ao conceito de Bildung. Veiculando uma comunicação intercultural e um modelo de interpretação, a tradução mostra de modo exemplar a problemática da leitura do espaço cultural europeu no início do século XIX e a apropriação de tudo que é estrangeiro. 
O estudo da dimensão estrangeira, isto é, no nosso caso, o estudo da dimensão europeia, não pode ser realizado sem recorrer ao uso de procedimentos de avaliação e de comparação, como por exemplo, os processos de aculturação. A literatura comparada vive do exercício alternado de três práticas: o estudo da dimensão estrangeira, a comparação de textos e a elaboração de modelos mais ou menos "teóricos". Parece que a segunda orientação é a mais praticada, a comparação de textos.

Podemos finalmente identificar a alteridade, a diversidade e a singularidade principalmente de um ponto de vista comparatista. Segundo os termos de Pageaux, cada vez que há uma linha divisória, uma linha fronteiriça entre duas culturas, cada vez que o homem inicia, pela descoberta do outro, um diálogo com este outro e com ele mesmo, cria-se desse modo momentos em que a consciência de si revela conhecimento e redistribuição imediata deste encontro e diferença, palavras-chaves da literatura comparada.

\section{Notas}

1. Littérature Comparée et Comparaisons : Daniel-Henri PAGEAUX. 11/04/2015, Editora: SFLGC (Vox Poetica) URL:http://www.vox-poetica.org/sflgc/biblio/comparaisons.htm. Conferência ministrada na Sorbonne em 06 de novembro de 1997 dentro dos trabalhos do Collège International de Littérature Comparée organizados por Pierre Brunel, e publicada na RLC / Revue de Littérature comparée, 1998/3.

2. Claire Gaspard (Université de Caen) : «Madame de Staël et les historiens de la Révolution ».

3. La traduction, principe de perfectibilité, chez Mme de Staël, Jane Elisabeth Wilhelm, Meta, n. 49/3, 2004. 


\section{Referências}

AUREVILLY, J. Barbey de. Des Euvres et des hommes. 5e volume. La littérature comparée. Col. Que Sais-Je, nº 499, 1878a

AUREVILLY, J. Barbey. "Mme de Staël". In : Les oeuvres et les hommes. Paris: Amyot, 1878. T.5. Disponível em: http://gallica.bnf.fr/ark:/12148/bpt6k204451t. Acesso 13 abril 2015. 1878b.

GASPARD, Claire. "Madame de Staël et les historiens de la Révolution". In : CONFERÊNCIA DE ABERTURA DO $133^{\circ}$ CONGRESSO SOBRE MME DE STAËL, 2000.

GUYARD, Marius-Francois. La littérature comparée. Paris: Presses Universitaires de France, 1951

HULST, Lieven d'. Cent ans de théorie française de la traduction. Lille: Presses universitaires de Lille edition, 1990.

MICHELET, Jules. Les femmes de la révolution Paris: Chamerot, 1855.

PAGEAUX, Daniel-Henri Litterature Comparée et Comparaisons. In: Vox Poética, Disponível em: http://www.vox-poetica.org/sflgc/biblio/comparaisons.htm. 15 set. 2005.

STAËL, Madame de. Oeuvres complètes de Madame la baronne de Staël-Holstein, Paris, Firmin-Didot et Treuttel et Wurtz, 1838.

STAËL, Madame de. De la Littérature. Paris: Flammarion, 1991.

STEINER, George. Nenhuma Paixão Desperdiçada. Tradução de Maria Alice Máximo. Riode Janeiro: Editora Record, 2001.

. De l'Allemagne, Paris, Garnier-Flammarion, chronologie et introduction par Simone Balayé, 1968. 
. Essai sur les fictions suivi de De l'influence des passions sur le bonheur des individus et des nations, préface de Michel Tournier. Paris: Editions Ramsay, 1979.

. Do espírito das traduções. In: Antologia bilingüe - Clássicos da Teoria da Tradução. Volume 2 - Francês/Português. Trad. Cláudia Borges de Faveri \& Marie-Hélène Catherine Torres (Org.). Florianópolis: NUT, 2004.

TODOROV, T. « Le croisement des cultures ». Communications, 43, p. 5-24, 1986.

WILHELM, Jane Elisabeth. La traduction, principe de perfectibilité, chez Mme de Staël. Meta, Montréal, volume 49, numéro 3,s p. 692-705, set. 2004

Recebido em: 15/09/2014

Aceito em: 04/12/2014 